\title{
Robert Wilson: Método de workshop ${ }^{1}$
}

\author{
Maria Shevtsova \\ Goldsmiths University of London, Londres, Reino Unido \\ E-mail: m.shevtsova@gold.ac.uk \\ Tradução: Marcia Berselli \\ Universidade Federal de Santa Maria - UFSM, Santa Maria, Brasil \\ E-mail: bersellimarcia@gmail.com \\ Tradução: Fernanda Abegg \\ Universidade Federal de Santa Maria - UFSM, Santa Maria, Brasil \\ E-mail: fernandabegg@gmail.com
}

\section{Resumo}

Na primeira parte do capítulo Métodos, elementos e princípios, nomeada Método de Workshop, Maria Shevtsova apresenta o método de criação desenvolvido por Robert Wilson, particularmente a partir da utilização dos livros visuais. A partir de entrevistas com Wilson, a autora destaca a base de pensamento do trabalho do encenador, indicando a importância da linguagem gestual e do movimento de todos os elementos em suas criações. Através da descrição do trabalho de mesa [workshop table] e dos workshops com atores, a autora apresenta a equalização de todos os elementos presentes na encenação, aspecto fundamental no trabalho de Robert Wilson.

\section{Palavras-chave}

Robert Wilson. Processo de criação.

Livros visuais. Storyboards.
Abstract

In the first part of the chapter Methods, Elements and Principles, named Workshop Method, Maria Shevtsova presents the method of creation developed by Robert Wilson, particularly from the use of visual books. From interviews with Wilson, the author highlights the basis of the work of the director, indicating the importance of sign language and the movement of all elements in their creations. Through the description of the workshop table and the workshops with actors, the author presents the equalization of all the elements present in the staging, a fundamental aspect in the work of Robert Wilson.

Keywords

Robert Wilson. Creative Process.

Visual Books. Storyboards. 


\section{Do storyboard ao livro visual}

O fato de Wilson não ter uma teoria não significa que ele não reflita. Nas suas entrevistas ele pensa sobre sua prática, apesar de sua timidez com palavras, e observações advindas destas entrevistas, para este capítulo, são essencialmente a base de pensamento de seu trabalho com performance. Além disso, há várias formas de pensar - por meios visuais, musicais e outros meios não-verbais, com o corpo (especialmente no caso de dançarinos), e em silêncio. Wilson pensa em todos esses modos e começa com seus storyboards (o termo da técnica fílmica de esboçar cenas a serem filmadas), o qual ele parece ter utilizado pela primeira vez em Einstein. Ele estava prestes a chamá-los de "livros visuais" [visual books]. Tudo esboçado neles, cena por cena, usualmente com textos ao lado ou abaixo de seus desenhos, são um suporte para a preparação de suas produções assim como para a fase de encenação. Os espaços e formas de suas cenas são configurações mais do que ilustrações, mas eles, no entanto, resumem em imagens a estrutura geral de um trabalho, quanto tempo terá, como as cenas vão parecer e o que acontecerá nelas. Wilson destaca:

como cenas diferentes podem se relacionar umas com outras, se pode haver uma declamação musical ou algo falado, um dueto ou algumas canções. Eu faço isso com desenhos para ver a construção, para ver como a história é contada visualmente, como a arquitetura parece no tempo e espaço. (ENRIGHT, 1994, p. 16)

Os "livros-visuais" são o primeiro passo de Wilson para o que, na mesma entrevista, ele chama de o "livro-visual" (pronome coletivo) o qual, segundo ele, o Teatro

\footnotetext{
1 SHEVTSOVA, Maria. Robert Wilson. London \& New York: Routledge, 2007. Tradução do subcapítulo: A workshop method - parte do segundo capítulo Methods, elements and principles.
}

Ocidental não desenvolveu adequadamente: "Shakespeare, Goethe, Schiller, Molière, Racine, Tennessee Williams são homens que escreveram palavras, que escreveram literatura para o teatro" (ibid. p. 18). O treinamento de ator contemporâneo seguiu os passos, se tornando "tão intelectual" que negligencia a mais simples técnica corporal - sentar em uma cadeira, caminhar pelo palco; e nem pode começar a se comparar com o treinamento do teatro Balinês, no qual existem "trezentos a quatrocentos movimentos apenas para o olho" (ibid.). Os "Iivros-visuais" de Wilson, então, podem ser parafraseados, do contexto imediato da sua discussão, como "linguagem gestual":

Nós simplesmente não desenvolvemos uma linguagem. Se você analisar o teatro clássico no Japão - Nô, Kabuki ou o que for - é gasto tanto tempo aprendendo um gesto como no som que eles produzem ou no poema que está sendo falado ou na história que está sendo contada. Como você para em uma peça Nô?... Como você pega um leque, como você segura... qual é o traço do dedo no espaço?... Como você coloca o movimento? Eles têm uma linguagem teatral desenvolvida pelo corpo que está simplesmente faltando em nosso teatro. Nós desenvolvemos isto na dança. (ENRIGHT, 1994, p. 18)

Existe um eco aqui da chamada de Ariane Mnouchkine por "uma arte do ator", que tipifique "a grande tradição das formas Orientais, quer Japonesa, Indiana, Balinesa" e é antitética à Ocidental "arte do texto" (SHEVTSOVA, 1995-96, p. 8). E, de fato, a admiração de Wilson não apenas pelo teatro clássico Japonês, mas também pelo Balinês (com menos impacto no seu estilo do que no de Mnouchkine) o levou, de um lado, até Suzushi Hanayagi, que foi treinado na escola de dança tradicional de jiuta-mai (MOREY e PARDO, 2003, p. 99) e, por outro, para I La Galigo. Aqui cenas honram uma 
rica performance histórica: pássaros voam nos galhos ${ }^{2}$; gatos rondam, com imensos arcos como cauda; homens "remam" cruzando os mares com os quadris pelo chão - todos com corpos ágeis, passos leves e dedos velozes. Estas cenas graciosas coexistem harmoniosamente com as posições e gestos hieráticos, típicos da abordagem de Wilson. Tomemos, por exemplo, como a Princesa da história dá a luz, o momento final sugerido por meio de véus desenrolando-se do seu corpo. A cena final, na qual a antiga deusa do arroz indica a passagem do tempo com seu leque (performada por um mestre Indonésio de 77 anos) é a síntese da simplicidade, e uma impressionante demonstração de como você "segura" um leque.

Apesar do toque de "Orientalismo" no discurso de Wilson sobre performance do Oriente - e aspectos do seu teatro que ecoam o paradigma "intercultural" do Oriente-Ocidente dos anos 1980 e 1990 - Wilson não está minimamente interessado em exotismo ou apropriação. Seu objetivo é estabelecer uma linguagem gestual adequada às suas produções, e ele mantém esta linguagem em mente conforme desenha seus livros visuais. Os detalhes mais específicos são determinados apenas quando eles são experimentados e testados, inumeráveis vezes, no tempo real e no espaço disponível para ensaios. Wilson pode não ter uma teoria para checar ou provar, mas o seu trabalho com todos durante o processo de produção é meticuloso e exigente.

A narrativa a seguir, referindo-se às entrevistas com Wilson, define suas produções, como se deve, uma vez que o método de Wilson e seus princípios são incorporados nestas produções, pelos meios verbais e não-verbais. A ideia da "corporifi-

2 Imagens suprimidas na tradução, por conta de direitos autorais $(\mathrm{NdT})$. cação" é especialmente adequada a Wilson porque ele nunca parou de pensar no seu trabalho como dança, a mais corpórea, arte-no-corpo de todas elas. E o princípio da dança afeta todos os elementos usados por ele a tal ponto que nada nunca está completamente estático, nem mesmo objetos, luzes sozinhas, aquela iluminação em movimento que fez dele um designer de luz incomparável entre os demais. Meus exemplos da sua produção conduzem a, ou são corroborados por, entrevistas com Wilson.

\section{Workshops}

A preparação para um projeto geralmente começa vários anos antes, Wilson costuma dizer que ele precisa de muito tempo, especialmente para montagens como Death Destruction and Detroit e the CIVIL warS, para "juntar ideias, informações, achar um tema, um gesto, um texto, uma cor, uma linguagem, uma palavra, iluminação" (FRIEDL, 1982, p. 55). Desde os anos 90, e particularmente desde que ele intensificou seu trabalho sobre os clássicos europeus, o tempo de preparação tem sido reduzido, geralmente para um ou dois anos de antecipação, e com consulta prévia a sua equipe cujos membros executam com excelência as suas respectivas tarefas. Alguns dos quais têm trabalhado com ele por décadas. Outros vêm e vão, e ainda há outros que colaboram com ele em vários projetos em sequência e não mais retornam, usualmente por razões circunstanciais. Ann-Christin Rommen, que tem sido a assistente de direção de Wilson desde a sessão de Colônia de the CIVILwarS, é um dos membros permanentes do seu time, e algumas vezes creditada como sua co-diretora. Michael Galasso, que escreveu a música para Peer Gynt, é um exemplo do segundo tipo de participante e contribuiu para projetos especí- 
ficos desde The Life and Times of Joseph Stalin. Monica Ohlsson do Stadsteatern em Estocolmo, que foi dramaturga de Wilson no Three Sisters and A Dream Play e também em Peer Gynt, é um exemplo do terceiro tipo. O ponto essencial é que o trabalho colaborativo de Wilson envolve uma seleção de um agrupamento de colaboradores de acordo com o projeto. Este tipo de sistema em equipe é bem diferente da malha apertada que ocorre na colaboração de montagens em companhias como a Maly Drama Theatre de São Petersburgo, pegando o mais notável contraste (SHEVTSOVA, 2004).

Uma vez que um trabalho tenha sido decidido ou encomendado, ele geralmente passa por três fases, começando com o que Wilson chama de "trabalho de mesa" [table workshop] - uma reunião geralmente entre Wilson, Rommen e um dramaturgista, cenógrafo, figurinista e compositor, com mais pessoas incluídas quando necessário. Eles discutem sobre a peça para mapear o seu conteúdo narrativo. No caso de Peer Gynt, por exemplo, produzida pelo Det Norske Teatret em Oslo, Rommen e Ohlsson resumiram cada cena na linha de "Peer faz isso, ele diz aquilo, a sua mãe (ou outro alguém) responde e então isto ocorre com tal e tal consequência". O esqueleto da história levou Wilson a perguntar várias questões - por exemplo, onde $\mathrm{X}$ evento ocorreu, quando ocorreu, em qual horário do dia isto ocorreu e quantas pessoas estavam envolvidas. Conforme o resumo procede e mais questionamentos são feitos, Wilson desenha, visualizando seus pensamentos. Por isso, é claro, a ideia dos seus "livros visuais".

A primeira resposta de Wilson é prever a estrutura espacial para cada cena e se ela vai ser formatada por uma gota de tinta, fotografia reproduzida, tela transparente, ou recortada em algum material altamente resistente, que irá deslizar das coxias ou cair do urdimento para configurar a cena. DetaIhes do tempo podem aparecer pela sombra ou pelas pinceladas grosseiras. Detalhes da configuração quase nunca são desenhados pictoricamente no formato de pinturas de paisagens. Até as montanhas de Peer Gynt são grosseiramente marcadas por fortes traços geométricos. Figuras indeterminadas aparecem ocasionalmente, como no livro visual de Peer Gynt, para indicarem a sua relação com o espaço. Entretanto, a relação de espaço e movimento entre os performers são definidas nos ensaios, nos quais Wilson ajusta a posição, postura, direcionamento de cabeça ou mão, ou qualquer aspecto do vocabulário gestual que precise ser posto em foco. Nos ensaios de Peer Gynt estava evidente que alguns de seus desenhos eram mnemônicos, lembrando a ele o que ele havia inicialmente imaginado, embora o desenvolvimento das cenas tivesse ocorrido somente quando ele trabalhou com os atores.

Além de produzir livros visuais, o trabaIho de mesa é crucial para o dramaturgista cuja a tarefa é editar um texto assegurando que as fundamentações da narrativa continuem mais ou menos intactas. O diálogo é encurtado e alguns até omitidos, mas as decisões sobre cortes são um processo dual que depende da indicação verbal dos colaboradores e das sugestões que Wilson dá a eles através do seu livro visual; a parte difícil para o dramaturgista vem depois da mesa de trabalho, em todo aquele ajuste textual posterior embasado na atuação dos performers e nos ajustes de Wilson. Os designers começam sua pesquisa durante o trabalho de mesa. Discussões também podem ser levantadas sobre se e quando acessórios deveriam ser fixos ou móveis, os desenhos de Wilson fornecendo sugestões, mais uma vez. O compositor começa a pensar sobre tipos possíveis de músicas ou efeitos sonoros. Essa ativida- 
de não tem a intenção de unificar a produção, mas dar a cada colaborador um ponto de referência para que nada seja acidental.

As várias colaborações são eventualmente colocadas juntas coerentemente. Entretanto, Wilson trata os elementos em questão como entidades separadas desde o princípio para que, nas suas próprias palavras, "eles não arrisquem ilustrar um ao outro mutuamente, não são dependentes um do outro" (GRILLET e WILSON, 1992, p. 13). Ao respeitar sua autonomia, Wilson convém a eles igual importância. Ele observa:

$\mathrm{Na}$ tradição europeia, o texto é o elemento mais importante no palco. No meu teatro todos os elementos são iguais: o espaço, a luz, os atores, os sons, os textos, os figurinos, e os acessórios. Eu penso que é algo que Brecht tentou trazer para o teatro alemão, também. (TESCHKE, 1999, p. 14)

Bons sete anos antes, Heiner Muller também invocou Brecht para elucidar a prática de Wilson, argumentando que "a questão essencial do trabalho teatral de Wilson é a separação dos elementos, um dos sonhos de Brecht" (ibid.).

A segunda fase envolve a seleção do elenco (em alguns casos também a finalização desse elenco juntamente com os produtores) e o primeiro workshop com os atores. As audições parecem um pouco mecânicas. Atores são tipicamente solicitados a caminhar, sentar, falar um texto curto, cantar algumas frases e repetir um padrão de movimento demonstrado por Wilson. Rommen reivindica que "ali você consegue ver tudo" (7 de fevereiro de 2005). Meses podem se passar antes do primeiro workshop com os atores, que dura duas ou três semanas, e o qual Wilson, retomando seus primeiros trabalhos, conduz como uma "peça silenciosa", sem nenhum diálogo, mas frequentemente com música. Os atores sabem o texto em questão e algumas vezes já o performaram no teatro convencional baseado em texto, como foi o caso, por exemplo, do ator que performou o antigo Peer Gynt. (Wilson teve três atores para o papel, inspirado pela organização de lbsen da peça em torno de três quadros de idade para Peer - jovem, meia-idade e velho.) O intuito da peça silenciosa é para familiarizar os atores com a linguagem performática de Wilson, a qual eles aprendem como dançarinos aprendem uma coreografia fixa e em muito similar com o mesmo modo repetitivo de rotina. Enquanto eles trabalham dessa forma, Rommen e o dramaturgista geralmente anotam onde o diálogo deve ser inserido e quão longo deveria ser.

Conversas durante os workshops de atuação são explicativas, basicamente fornecendo ganchos para dentro do universo de Wilson. Afinal, ser solicitado para gesticular e se mover da forma impessoal e impassível à maneira de Wilson - robótico, quando performado superficialmente, gracioso e significativo, quando feito com convicção - não é o ideal de atuação para a maioria dos atores, e isto pode ser particularmente intimidante quando os atores não viram uma produção de Wilson, nem mesmo em vídeo. Wilson, que é completamente ciente disso, tenta conectar sua abordagem com algo familiar para eles. Pegue, por exemplo, as observações dele do primeiro workshop para Ozeanflug (Oceanflight) [O Voo sobre o Oceano], a peça radiofônica de Brecht encenada por Wilson no Berliner Ensemble em 1998. A ideia de montar a peça para o centenário de Brecht veio de Heiner Muller logo antes de sua morte em 1995. Holger Teschke, o dramaturgista da produção, escreve:

O trabalho com os atores começa. Wilson explica seus conceito para a equipe. Quando explicando suas ideias para a peça, Wilson falou de Brecht e Weigel, de quem ele viu encenar "The 
Mother" em Paris. Ele falou da simplicidade e clareza dos seus movimentos. Ele contou de sua amizade com Heiner Muller, relembrou anedotas do seu trabalho conjunto na parte alemã de the CIVIL warS e em Hamletmachine em Hamburgo e Nova York. Ele também descreveu a sua concepção de teatro. (TESCHKE, 1999, p. 14)

Muller tem sido associado com o Berliner Ensemble desde os tempos de Brecht e também foi o seu Diretor de Arte, então a lembrança pessoal de Wilson era significativa para a companhia montada. Infelizmente, Teschke não mencionou a peça silenciosa, crucial para esta fase.

O primeiro workshopé também quando os desenvolvimentos desde a discussão de mesa são testados e revistos. Teschke observa que durante este período para Ozeanflug:

\begin{abstract}
os designs do palco foram mostrados e parcialmente montados pela primeira vez, as instalações de iluminação do teatro foram examinadas e testadas, e versões de música e texto foram discutidas e desenvolvidas. Tudo isso ocorreu simultaneamente em várias salas de trabalho e espaços de ensaio em muitas mesas, usando muitos modelos de pal$c o$, e algumas vezes maquetes em tamanho real das paredes do palco; o processo pode parecer um pouco caótico para os de fora. (TESCHKE, 1999, p. 13-14)
\end{abstract}

Isto é uma versão intensiva do "trabalho de sempre" do fazer teatral, composto pelas expectativas particularmente altas dos colaboradores que trabalham independentemente ao longo de seus respectivos trajetos e ainda, paradoxalmente, têm de estar no caminho certo para "encaixar" dentro do "arranjo texturizado" constituindo uma produção. Em outras palavras, a contribuição deles não é tanto orgânica quanto especializada; e a perícia deles garante sua independência. O paradoxo da independência/ consenso se tornou uma característica tão forte do método de Wilson na última década - coroado por notável eficiência (apesar de aparente e real caos) - que isto sugere o modelo corporativo referido no próximo capítulo. O que não significa negar a maestria - com frequência superlativamente imaginativa - das produções que são finalmente feitas.

A terceira etapa envolve o que pode ser chamado de diferentes "momentos", começando pelo segundo workshop com os atores. O intervalo de tempo entre os workshops com os atores varia - por exemplo, nove meses entre o primeiro e segundo para Peer Gynt, sete meses para Ozeanflug. Nesse ponto, é esperado dos atores que tenham memorizado a partitura de movimentos e internalizado seus tons, ritmos e falas. Partitura aqui ecoa intencionalmente o termo de Meyerhold (que se originou com Stanislavsky) pela ideia de que os movimentos podem ser tão precisos como notas musicais e seguem a mesma lógica intrínseca sem nenhum recurso ao comportamento "natural" ou suas justificações psicológicas. O procedimento de Wilson, embora não seja formulado por ele nesses termos, pode ser visto sendo uma linha de pensamento similar, o que não é surpresa dada a afinidade de suas práticas com as práticas modernistas do início do século XX. O principal propósito do segundo workshop com os atores é conectar o trabalho silencioso e o verbal e ajustar um ao outro. Quaisquer alterações textuais necessárias são feitas aqui pelo dramaturgista (e qualquer diálogo é re-inserido se muito disso tenha sido cortado) para o que se torna o texto "final" ao término do workshop.

O próximo "momento", o qual geralmente tem continuidade do segundo workshop com atores, é o tempo real de produção e ensaio, e dura de três a cinco-seis semanas, dependendo dos acordos contratuais entre Wilson e o respectivo teatro. A iluminação, embora antecipada até certo ponto nos li- 
vros visuais e workshops, é realmente feita durante essa terceira fase. Não há fórmula fixa para como a divisão de trabalho do time vai engrenar. Wilson, por exemplo, passou pouco tempo no texto para Peer Gynt: a revisão de Ohlsson foi rápida e os atores assumiram com firmeza suas falas. Em contraste, Teschke destaca que para Ozeanflug Wilson passou "uma quantidade de tempo incomum trabalhando no texto, procurando continuamente por novas soluções para fazer jus à linguagem da peça didática de Brecht para o rádio" (TESCHKE, 1999, p. 15). Teschke também observa que Rommen "trabalhou através de constelações cênicas com os atores" (ibid), enquanto que, do que eu pude perceber pelos ensaios de Peer Gynt, essa responsabilidade caia primariamente sob Wilson. Rommen, da sua parte, havia vindo antes desses ensaios "para posicionar o texto com os atores para que ele pudesse viver dentro daqueles movimentos [estabelecidos pelo trabalho silencioso de Wilson] e fazer sentido" (7 de fevereiro de 2005).

Normalmente, Rommen trabalha com os atores mais como um "maître de danse" que complementa o que o coreógrafo da companhia de balé planejou; e, nessa função, algumas vezes ela substitui Wilson durante o segundo workshop. A terceira fase encaixa a produção "apropriadamente" dentro do que Wilson gosta para organizar uma pré-estreia uma semana antes da estréia oficial. Algumas performances em pré-estréia são gratuitas (Peer Gynt em Oslo) outras são pagas (The Black Rider em Londres), isto depende da política da produção do teatro. Claro, a presença dos espectadores afeta os performers, e Wilson usa o feedback entre palco e plateia, quando pode, para afinar detalhes, incluindo detalhes da iluminação.

Qualquer que seja a variação que possa ocorrer no plano de ação, a autonomia dos membros da equipe, conforme eles prosseguem na sua pesquisa, pressupõe uma fé coletiva no seu resultado a longo prazo, assim como na sua cooperação quando eles convergem. O pequeno artigo do famoso crítico italiano Franco Quadri no programa de I La Galigo lança a atenção a esse encontro de estética, autoridade, divisão do trabalho, organização e convicção:

Por vários meses a Diretora Artística Restu I. Kusumaningrum procurou por toda a Indonésia, escolhendo vários dançarinos educados desde a infância nas formas tradicionais para se apresentarem à uma seleção final feita por Wilson, que conduziu-os por variações de movimentos baseados no seu trabalho, como aconteceria no workshop que começou em 2001. Como a própria Restu conta, "O maestro veio em intervalos regulares, por vários dias muito intensos, nos quais ele revisou o trabalho que ele havia feito previamente e adicionando novos toques, frequentemente com um fantástico sabor surreal, sem nunca perder de vista a base tradicional." (QUADRI, 2004, p. 69)

"Seleção final" e "maestro" indicam inequivocamente a autoridade investida em Wilson. Mesmo assim, seria um erro acreditar que Restu foi simplesmente uma engrenagem na máquina, seus esforços se agruparam sob a "visão" estética de Wilson. Nos cinco anos de preparação necessários, ela exercitou sua iniciativa tanto quanto o "Mestre Javanês" o fez, "quem escolheu músicas históricas do repertório indonésio, prestando atenção às tradições religiosas, às quais ele deu então um toque contemporâneo" (ibid). A autonomia necessariamente teve que entrar em cena para trazer a produção a um sucesso completo. Quadri diz sobre:

Com cada parte tão completamente pesquisada, o espetáculo foi, portanto, capaz de ser reunido extremamente rápido nas últimas três semanas no Teatro da Esplanada de Singapura, onde a acumulação de cenas para 
a montagem, apesar de sua complexidade, se fundiu em algo extremamente natural, graças à magia da imaginação. (QUADRI, 2004, p. 69)

A tensão criativa entre a "parte tão completamente pesquisada" e o todo, entre os membros da equipe e o diretor, e entre o trabalho deles e a "visão" de Wilson é decidida na produção. Este tipo de tensão é característica de todos os trabalhos colaborativos independentemente de como o seu processo se diferencia conforme cada grupo colaborativo. Wilson não escapa disso e, se for o caso, seu total comprometimento à ideia que a arte substitui todas as outras vontades e desejos coloca a balança a seu favor, dando a ele a palavra final nos detalhes da produção compreendidos como um todo coerente. A sua convicção de que a arte é um valor supremo em si mesma é qualquer coisa menos pós moderna, e a sua atitude o une aos modernistas do século $X X$, mais uma vez. Suas conexões mais próximas nesse sentido são a devoção de Edward Gordon Craig à Arte, a qual Wilson corresponde, o ideal de Craig do criador abrangente, o qual Wilson modifica através da sua abordagem de equipe, e o objetivo de Craig de se liberar do texto através do movimento (Craig, 1978), o qual Wilson torna real em sua "peças dançadas" e "óperas silenciosas".

\section{Referências}

CRAIG, Edward Gordon. On movement and dance. Ed. Arnold Rood, London: Dance Books, 1978.

ENRIGHT, Robert. A Clean, Well-lighted grace: An interview with Robert Wilson. In: Border Crossings, 13:2, 1994, p. 14-22.
FRIEDL, Peter. Une perception autre: entretien avec Bob Wilson. In: Théâtre/Public 48, 1982, p. 54-9.

GRILLET,Thierry; WILSON, Robert. Wilson selon Wilson. In: Theatre/Public 106, 1992, p. 8-13.

MOREY, Miguel; PARDO, Carmen. Robert Wilson. Barcelona: Ediciones Poligrafa, 2003.

QUADRI, Franco. The Complete Enchantment. In: I La Galigo. Milan: Change Performing Arts, 2004, p. 69-71.

ROMMEN, Ann-Christin. Unpublished interview, 2005.

SHEVTSOVA, Maria. A Theatre that Speaks to Citizens: Interview with Ariane Mnouchkine. In: Western European Stages 7:3, 1996, p. 5-12.

SHEVTSOVA, Maria. Dodin and the Maly Drama Theatre: Process to Performance, London: Routledge, 2004.

TESCHKE, Holger. Brecht's learning plays - a dance floor for an epic dramaturgy. A rehearsal report on Robert Wilson's ozeanflug at the Berliner Ensemble, Trad. Joe Compton. In: TheatreForum 14, 1999, p. 10-16.

Recebido: 24/04/2019 Aprovado: 22/10/2019 